Disponível em

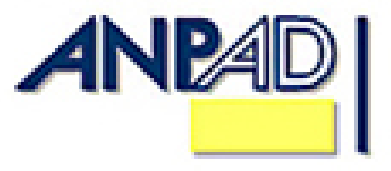
http://www.anpad.org.br/rac

RAC, Curitiba, v. 15, n. 4, art. 6, pp. 670-688, Jul./Ago. 2011

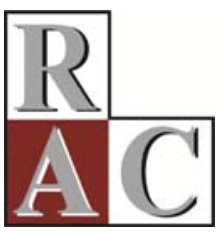

$(\mathrm{cc})$ EY-NO

\title{
A Percepção e as Estratégias de Ação do Pesquisador de Café em sua Rede Colaborativa
}

\section{The Perception and the Action Strategies of Coffee Researchers in their Collaborative Network}

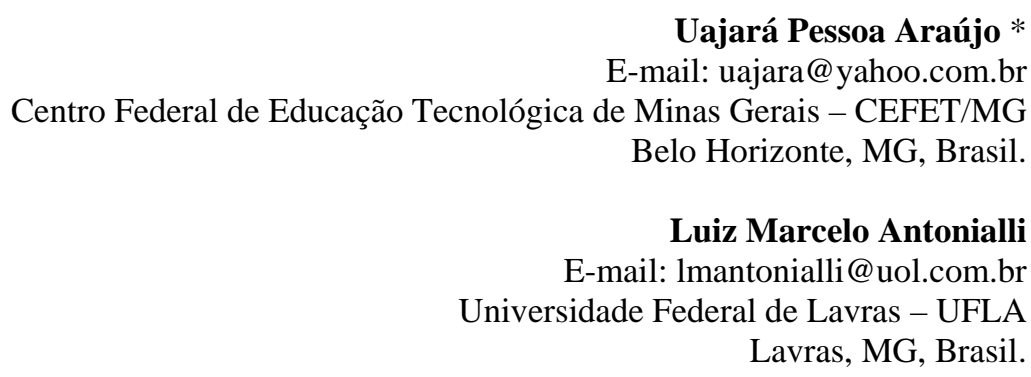

Fábio Muller Guerrini E-mail: guerrini@sc.usp.br Escola de Engenharia de São Carlos da Universidade de São Paulo - EESC/USP

São Carlos, SP, Brasil.

Renato Ferreira de Oliveira E-mail: renatofo@eafmachado.gov.br Instituto Federal de Educação, Ciência e Tecnologia Sul de Minas Gerais - IFET

Machado, MG, Brasil.

* Endereço: Uajará Pessoa Araújo

CEFET/MG, Campus II, Avenida Amazonas, 7675, Bairro Nova Gameleira, Belo Horizonte/MG, 30510-000.

Copyright (C) 2011 RAC. Todos os direitos, até mesmo de tradução, são reservados. É permitido citar parte de artigos sem autorização prévia, desde que seja identificada a fonte. 


\title{
Resumo
}

Esta investigação investigou o papel da percepção, seus condicionantes e seus efeitos na lógica da ação dos pesquisadores na formação de parcerias, no âmbito da rede subjacente ao Consórcio Brasileiro de Pesquisa e Desenvolvimento do Café. Abalizado pela teoria institucional e pela teoria de redes, partiu-se da suposição de que a percepção dos agentes (sobre a sua posição/localização estrutural, os recursos disponíveis e a dinâmica de apropriação de recursos da rede) é significativa à medida que seria fator condicionante da estratégia de inserção dos pesquisadores na sua rede colaborativa. No estudo, recorreu-se: (a) à análise de conteúdo em entrevistas com pesquisadores; (b) à análise sociométrica de coautorias em artigos; (c) à análise sociométrica da escolha preferencial entre pesquisadores do café; (d) à análise multivariada de um banco de dados de subprojetos do Consórcio e de respostas a uma survey submetida aos responsáveis pelos subprojetos. Os resultados assinalam que o posicionamento estrutural do agente, ainda que relevante, não condiciona a percepção dos agentes e isso pode ter implicações nas suas estratégias de ação. Conjuminada a essa indicação, foi possível identificar um grupo de regularidades e lógicas de ação incidentes no conjunto de cientistas pesquisados. Seria nesse campo que o pesquisador praticaria a sua agência: onde monitora e percebe os recursos e as limitações da rede, se insere e aos colegas e mobiliza parcerias.

Palavras-chave: redes colaborativas; consórcio de pesquisa; gestão de P\&D.

\begin{abstract}
This study examined the role of perception, its grounds and effects on the logic of the action of researchers when forming partnerships in their underlying Brazilian Consortium network for Coffee Research and Development. Supported by the institutional theory and the network theory, it started out with the assumption that the perception of agents (regarding the structural position/location, the network resources and the dynamics of resource appropriation) is relevant as it would be a determining factor when it came to inserting researchers in their collaborative network. The study resorted to: (a) the content analysis of interviews with researchers; (b) the sociometric analysis of co-authorship; (c) the sociometric analysis of the preferential choice among coffee researchers; and (d) the multivariate analysis of a database of the consortium sub-projects and responses to a survey of those responsible for subprojects. The results point out that the structural position of the agent in its network, though significant, does not determine the perception of these agents and this may have implications for their strategies. Along with this statement, it was possible to identify a group of regularities as well as a set of logical actions on the part of the scientists under study. It would be in this field that the researcher would practice his agency, where he monitors and perceives the resources and limitations of the network in which he and his colleagues are included and form partnerships.
\end{abstract}

Key words: collaborative networks; research consortium; R\&D managment. 


\section{Introdução}

Redes colaborativas de pesquisa resultam de esforços, com grau variável de dirigismo, em fomentar a cooperação entre os pesquisadores, entre as entidades de pesquisa e entre essas e a indústria. Acredita-se que, quando cientistas se associam, eles trazem consigo conhecimentos e capacidades complementares que podem ser combinados em novos produtos ou processos, ao mesmo tempo que adquirem novas habilidades e se tornam mais conhecidos e portanto sujeitos a novos projetos (He, Geng, \& Campbell-Hunt, 2009). Admite-se, eventualmente, de forma acrítica, uma relação direta entre colaboração e resultados, tanto na criação ou invenção, quanto na exploração do conhecimento (Katz \& Martin, 1997). Uma segunda relação, ligando invenção, inovação e competitividade (Schumpeter, 1961), pode ser adicionada à equação, complementada pelas evidências da ineficiência, tanto da hierarquia quando do mercado, para a gestão do conjunto dinâmico de competências requeridas para fazer face aos desafios da contemporaneidade. Fato ou crença, ou até por mero isomorfismo, o resultado é a crescente difusão das redes colaborativas em diversos setores da ciência, mormente aquele aplicado e de alta tecnologia.

Tipicamente, estudos sobre redes colocam em evidência o papel da estrutura e das instituições, buscando correlacioná-las com o desempenho do arranjo. Assim é que a inovação e a aprendizagem passaram a ser tomadas como determinadas por características de redes, de atores na rede e das ligações entre atores: densidade, laços fortes e fracos, laços diretos e indiretos, pontes, vazios estruturais, centralização e outros indicadores estruturais. Tanto que, para Buskens e Yamaguchi (1999), a eficiência (o tempo requerido) para a difusão de informações é dependente da centralidade, do número de pontes, da densidade e de outras medidas de rede, enquanto para Ahuja (2000), a colaboração entre firmas beneficia os parceiros pelo compartilhamento de recursos. Esses benefícios seriam dependentes do número de laços diretos e indiretos e da presença de vazios estruturais. Nisso há coincidência com Hansen (1999): laços interdepartamentais fracos ajudam as equipes de desenvolvimento de projetos a encontrar conhecimento útil em outras unidades, mas impedem a transferência de conhecimento complexo, que tendem a requerer laços fortes entre as partes para ser transferido. Em oposição, estão Yli-Renko, Autio e Sapienza (2001), que também se depararam com uma correlação positiva entre vínculos de rede e interação social com a aquisição de conhecimento e, por sua vez, com a inovação, mas não restrita a ligações fortes. Para Rost (2011), uma rede fraca, aquela com alguns vazios estruturais, seria dependente de laços fortes para facilitar o surgimento de soluções criativas. Já Landry, Amara e Lamari (2001) constataram que o grau de inovação radical é maior com o aumento do capital relacional, enquanto a centralidade do agente e a densidade da rede foram encontradas como variáveis explicativas para a criação e a exploração de novas tecnologias (Gilsing, Nooteboom, Vanhaverbeke, Duysters, \& Oord, 2009).

Evidencia-se a primazia acentuada da estrutura (rede) sobre o resultado (inovação, aprendizagem), guiado por determinismo causal em detrimento de aspectos ligados à conduta estratégica dos atores envolvidos (agência) ou de seus atributos pessoais. No entanto o debate entre agência e estrutura está longe de ser resolvido, dado o seu caráter dual (Giddens, 1989): a existência de uma supõe a atuação da outra. Mesmo porque a refutação da linha determinista e a teorização para além da dicotomia: atomismo (prevalecência do sujeito) \& objetivismo (supremacia das estruturas sociais) tem base teórica sólida, para além de Giddens (1989), desde Berger e Luckmann (1966), bem como em Bourdieu (1997) até os trabalhos de pesquisadores que se dedicaram aos estudos de redes, como Burt (1980), Granovetter (1985) e Lin (1999). É justamente sobre esse embasamento, endereçado à fundamentação teórica do artigo, que se busca investigar uma rede específica: aquela informal e subjacente ao Consórcio Brasileiro de Pesquisa e Desenvolvimento do Café (CBP\&D/Café), voltando-se para a percepção de seus pesquisadores sobre aspectos relevantes para as suas estratégias de investimento e mobilização de recursos dentro do arranjo.

Tal rede colaborativa foi escolhida como objeto de estudo, devido a uma série de premissas: (a) o café é ainda fonte significativa de renda e de divisas para o país; (b) a pesquisa brasileira em café é de primeira linha; (c) o Consórcio é um arranjo inovador dentro da pesquisa nacional, com centenas de 
pesquisadores e dezenas de entidades associadas; e (d) o Consórcio não foi até então escrutinado com a profundidade requerida. Daí, postula-se que uma pesquisa sobre o Consórcio atenderia aos requisitos de relevância, pertinência, adequação, atualidade e oportunidade.

O objetivo desta investigação foi expor a percepção dos pesquisadores de café sobre a sua rede e discutir a lógica de suas ligações. As redes são vistas, objetivamente, como estrutura que conecta nós. Em uma rede de pessoas, os nós são ativos: percebem e agem de acordo com essa percepção. Dessa forma, o problema da pesquisa foi formulado com o seguinte enunciado: qual é a percepção do pesquisador de café sobre a sua rede colaborativa e como isso afeta as suas estratégias de ação? Essa questão se desdobra em como os pesquisadores avaliam (percebem) a rede e a sua posição nesta rede, traçam e implementam estratégias, medem resultados e tentam interferir na estrutura que, ao mesmo tempo, facilita recursos e impõe restrições. Tais indagações foram encaminhadas por meio dessa pesquisa descritiva, mediante o emprego de métodos quantitativos (análise descritiva e de conglomerados de dados coletados de uma survey) e qualitativos (análise de conteúdo de entrevistas junto aos pesquisadores), algumas vezes triangulados.

É conveniente ressaltar que a opção pelo ente fundamental da pesquisa recaiu sobre o pesquisador e não sobre a organização de que ele faz parte, por se debitar a ele o papel mais relevante na formação das parcerias. Dessa forma, partiu-se da premissa de que a percepção dos agentes sobre aspectos relevantes da rede tem papel relevante na estratégia de mobilização dos recursos disponíveis e na realização de novos investimentos.

Postula-se que a justificativa do trabalho se dá à medida que as redes colaborativas assumem mais espaço no cenário brasileiro de pesquisa e permanecem como fenômeno insuficientemente estudado, o que dá ensejo a pesquisas que buscam a sua compreensão e, eventualmente, proveem indicações úteis à sua gestão. Ainda mais quando há expectativas do Consórcio servir de modelo para outras iniciativas, como, por exemplo, no caso do desenvolvimento da indústria do álcool etílico, como aventado por alguns dos entrevistados.

Sumariamente, logo após uma breve revisão bibliográfica das redes colaborativas que se presta à contextualização desta investigação bem como à discussão da colaboração entre os cientistas, abordam-se a questão agente-estrutura e o papel das instituições, para depois se apresentar o objeto e os métodos empregados na pesquisa que levaram a um conjunto de constatações apresentadas e discutidas nos últimos tópicos deste artigo.

\section{Redes Colaborativas de Pesquisa}

É recorrente em estudos de redes colaborativas de pesquisa ligar esse modelo de governança à crença de que os centros de pesquisas e universidades são repositórios de conhecimentos e capacidades insuficientemente explorados e que estímulos indutores de esforços cooperados, multiinstitucionais e transdisciplinares, implicando a formação de redes, ampliariam o impacto positivo do recurso público empregado (Corley, Boardman, \& Bozeman, 2006; Katz \& Martin, 1997; Landry \& Amara, 1998; Rigby \& Edler, 2005) - mesmo que isso ainda mereça maior comprovação; existem alguns resultados empíricos que argúem pelo menos parte dessas proposições, como aqueles de Ynalvez e Shrum (2011) e Cummings e Kiesler (2007). Tais trabalhos contraditam as correlações positivas, tomadas comumente como verdadeiras, entre colaboração e volume de publicação e entre esforço multi-institucional e resultados de projetos, respectivamente - por sua vez, em aparente contradição aos achados, também empíricos, de Bercovitz e Feldman (2011), que correlacionam o esforço multi-institucional (universidade, instituto de pesquisa e/ou empresas), de pessoas experientes já conectadas entre si, com a obtenção de patentes.

Nessa linha, induzir e, eventualmente, gerir redes colaborativas passaram a ser preocupação da administração pública, cuja tarefa é afetada pelo status institucional alcançado pela ciência, com 
mecanismos de regulação e normas que favorecem a autonomia, mesmo em face da sociedade (Merton, 1979), circunscrevendo o pesquisador no campo da independência em detrimento da interdependência, cara aos arranjos em rede.

Pelo menos parte da tarefa é facilitada, quando os cientistas participantes de redes de uma mesma disciplina tendem a compartilhar ideias, usar técnicas semelhantes e se influenciar mutuamente. À medida que cientistas trocam ideias com seus pares e colaboradores sobre problemas, sobre métodos e sobre regras para analisar as evidências de pesquisas, é admissível esperar algum consenso, pelo menos em redes coesas. Ainda mais se o campo de pesquisa é limitado a um único paradigma, a evolução do conhecimento se dá dentro da continuidade e existem cientistas estrelas, tomados como referência, que atraem um número desproporcional de colaboradores e a atenção da rede, conseguem capturar um volume desigual de recursos e, por tudo isso, são centrais na rede e capazes de difundir suas idéias na comunidade (Moody, 2004).

De uma ou outra forma, caberia à estrutura (ou àqueles com legitimidade de coordenação) consolidar os valores, bem como harmonizar as percepções dos participantes, com o fito de criar e celebrar uma visão e um arranjo de objetivos compartilhados, tão mais complicados quanto maior for a dissimilaridade entre os membros da rede, uma vez que o resultado da rede derivaria da interação das estratégias de todos os envolvidos. Isso requer diligências para facilitar e estimular as interações; reduzir a complexidade e as incertezas, promovendo a troca de informação; administrar os incentivos à colaboração; assegurar uma distribuição apropriada de papéis e posições; mobilizar apoios e estimular as ligações e a comunicação entre os parceiros (Agranoff \& Macguire, 2001). Falhas em coordenação, principalmente na divisão de responsabilidades, poderiam explicar, por exemplo, a inesperada correlação negativa entre esforço colaborativo multi-institucional e o resultado de projetos de pesquisa (Cummings \& Kiesler, 2007).

Na literatura internacional vicejam trabalhos que aplicam a sociometria para retratar as redes colaborativas a partir das coautorias e das citações em artigos (He et al., 2009). Tais dados são públicos, de fácil acesso, históricos e disponíveis - e levam a sociogramas e a indicadores objetivos e verificáveis, admitidos como indicação de colaboração entre os cientistas (Katz \& Martin, 1997).

Desse conjunto de pesquisas merece destaque o trabalho de Newman (2004), que estudando redes em biologia, física e matemática, buscou revelar padrões de colaboração entre os cientistas, concluindo que um pequeno número de cientistas responde por uma grande parcela de artigos; pequeno número de pesquisadores tem grande número de parceiros, enquanto a maioria tem um número significativamente menor; a maior parte dos pesquisadores está conectada entre si, de alguma forma - e, portanto, as redes colaborativas seriam altamente coesas.

Voltando-se ao fenômeno da colaboração entre cientistas, é interessante apontar a compilação de Bozeman e Corley (2004) acrescida do trabalho de Landry e Amara (1998), que permitem derivar uma lista de razões para a colaboração. A colaboração seria induzida pela necessidade de acesso a conhecimento, de acesso a equipamentos e a recursos, de se obter visibilidade ou prestígio, de adquirir conhecimento tácito sobre uma técnica, de aumentar a produtividade, de ajuntar conhecimentos para resolver um problema complexo, de aumentar o número de publicações, de aumentar o número de inovações e de construir uma rede de colaboradores - e também, por divertimento ou por prazer.

Propensão ao esforço colaborativo seria maior, quando os envolvidos são experientes e trabalham ou trabalharam em mais de uma universidade ou empresa (Rijnsoever \& Hessels, 2011). Mas a colaboração não é natural ou espontânea - afinal, trabalho colaborativo seria difícil e demanda recursos financeiros e tempo, com problemas de comunicação e de compartilhamento de conhecimento, ainda mais aquele tácito, complexo e específico, o que coloca em risco muito dos investimentos que as empresas, governo e universidades alocam nas pesquisas transdisciplinares e multi-institucionais. A colaboração seria facilitada nos casos em que os parceiros já tenham colaborado no passado, possuam um conhecimento prévio do assunto, detenham as mesmas qualificações e trabalhem sob um mesmo paradigma científico. Contudo, à medida que essa homogeneidade implica redes densas e em facilidade de colaboração, ela reduz o potencial de trabalho 
realmente inovador para além do incremental, ao confinar as informações àquelas redundantes - no reconhecido trade-off entre compartilhamento de conhecimento e variedade, estudado por Porac et al. (2004).

\section{Estrutura e Agência em Redes}

Em reação à concepção atomizada, calcada na teoria da escolha racional de indivíduos que buscam o seu próprio interesse, cara aos modelos econômicos clássicos, a abordagem de rede trata das interações de indivíduos ou grupos, a partir de uma visão estruturalista, adotando a premissa de que o padrão de laços sociais dos agentes tem importância significativa para esses agentes - e cabe à análise de rede revelar esses padrões, seus condicionantes e consequências (Freeman, 2004).

Essa premissa corre o risco de ser extrapolada e tornada determinística, de condicionar o indivíduo à imposição estrutural, de conferir premência do todo social sobre os sujeitos humanos. Aqui se poderia configurar o imperialismo do objeto social, a estrutura "externa à ação humana, uma fonte de restrição à livre iniciativa do sujeito independentemente constituído" (Giddens, 1989, p. 13), o que teria levado D. Wrong (como citado em Granovetter, 1985) a reclamar da concepção supersocializada do homem: uma concepção de pessoas extremamente sensíveis a opiniões de outras e obedientes ao consenso revelado em normas e valores, internalizados por meio da socialização.

Seria possível admitir que o cerne da questão já se fizesse presente nos fundamentos de Berger e Luckmann (1966), que procuraram integrar os aspectos objetivista e subjetivista da vida social, tentando explicar como e porque o sentido subjetivo (externalização), se torna fato objetivo (objetivação) e então age de volta, quando se socializa a geração presente e futura (internalização), implicando a construção social da realidade.

Algo assemelhado é encontrado na postura estruturalista-construtivista de Bourdieu (1997) que defende a articulação dialética entre o objetivismo (estruturas sociais) e o subjetivismo (estruturas mentais). As estruturas objetivas existiriam no mundo social e nos sistemas simbólicos, independentemente da consciência e da vontade dos agentes (estruturalismo). O habitus e as estruturas sociais seriam constituídos em uma gênese social de esquemas de percepção, pensamento e ação (construtivismo). Ainda que improvável, o habitus poderia ser modificado (e com eles os condicionantes externos e as próprias práticas) por meio da crítica reflexiva.

Por outro lado, para Giddens (1989), em sua Teoria da Estruturação, a estrutura seria o conjunto de regras e recursos implicados, de modo recursivo, na reprodução social. Daí, as redes e outras parcelas institucionalizadas dos sistemas sociais teriam propriedades estruturais, se as relações estão estabilizadas espaciotemporalmente. Os agentes desempenhariam suas ações, utilizando o seu conhecimento de regras e os recursos disponíveis, eventualmente condicionados por sua posição no tecido social. Contudo os agentes, dotados de cognoscibilidade - sabem acerca do que fazem e por que o fazem - controlam e regulam continuamente o fluxo de suas atividades, como também monitoram rotineiramente aspectos dos contextos em que se movem. Eles têm a possibilidade ou, melhor, a agência: o poder de agir de forma diferente, de questionar racionalmente e negar a continuidade de mobilização daquelas regras dissonantes, e isso implicar a transformação da estrutura, agora tida como restrição, recurso e como resultado da ação humana, em movimento dinâmico e contínuo de retroalimentação, dotado de autorregulação reflexiva, decorrente do conhecimento que os agentes têm dos mecanismos de reprodução do sistema e o empregam na tentativa de usufruir suas vantagens.

Segundo Giddens (1989), em toda relação social existiria uma dialética de controle que envolvem o acesso assimétrico aos meios (recursos) - e a manipulação desses meios - pelos quais os agentes influenciam o comportamento uns dos outros. A amplitude da ação de um agente seria função das práticas que esse agente é capaz de executar, dentro do conjunto de regras e recursos da estrutura. 
As conjeturas desses autores, mais equilibradas (nem atomizada, nem supersocializada; não só estrutura, não só agência), podem revelar, como agência e estrutura, se estão simultaneamente presentes no desenrolar das práticas sociais. Tais proposições estão incorporadas em Burt (1980), Granovetter (1985) e Lin (1999), que criticam tanto a visão atomizada ou subsocializada quanto a visão normativa ou supersocializada dos fenômenos sociais, propondo, respectivamente, a perspectiva estrutural, o embeddeness e um modelo que oferece uma posição relevante a agência.

Para Burt (1980), preocupado com o desenvolvimento de uma visão integrada, segundo a qual atores e estruturas atuam em conjunto, as teorias sociais poderiam ser classificadas em função de forma com que se considera o ator. Se o ator é visto de forma atomizada, as alternativas de ação são avaliadas de modo independente pelos diferentes atores, em busca racional por maximizar sua satisfação - aqui o foco são os atributos pessoais dos atores; se o ator é visto pela forma normativa, eles são percebidos dentro de um sistema criado por relações interdependentes, utilizadas para atingir os objetivos desses atores, o que, com o passar do tempo, estimula o aparecimento de normas que são internalizadas e guiam os atores em sua interação; e, por último, se o ator é visto da forma estrutural, a ação do ator é tomada como guiada simultaneamente pela racionalidade na busca de seus interesses e pelo contexto social, sendo esse contexto social passível de ser alterado pelas ações futuras dos agentes, criando-se um sistema dinâmico e retroalimentado (Burt, 1980, 1982).

\section{Já para Granovetter (1985)}

os atores não se comportam ou decidem como átomos, fora do contexto social; nem aderem, de forma escrava, a um script preparado para eles por uma particular intercessão de categorias sociais em que eles recaíram. Sua ação está, em verdade, embedded em um sistema social concreto e em construção (p. 487).

Segundo Granovetter (1990), isso implicaria o rompimento com as concepções da ação humana sub ou supersocializada.

Parte das proposições de Burt (1980) e Granovetter (1985) foi encampada pela teoria do Capital Social, no bojo da qual é passível extrair algumas proposições úteis. Existem diversas acepções de Capital Social (Araujo, Antonialli, Brito, \& Guerrini, 2010), entre elas, as de Lin (1999), que foi encontrada mais relevante e aplicável a esta pesquisa. Para Lin (1999), o Capital Social poderia ser definido como (a) os recursos imbricados em uma estrutura social e que são acessados e mobilizados propositadamente; ou (b) como os investimentos em relações sociais, realizados por indivíduos, por meio dos quais eles mantêm os recursos já possuídos ou ganham acesso a outros recursos. Lin (1999) parte da premissa de que os indivíduos se relacionam para aferir benefícios: do fluxo de informação; da possibilidade de exercer influência naqueles que têm papel crítico em decisões que interessam ao agente; das credenciais sociais que as ligações sociais concedem ao indivíduo e do reforço da identidade, facilitado pelas relações sociais. Isso implicaria três elementos que interceptam estrutura e agência: estrutural (embeddedness), oportunidade (acessibilidade) e aspectos orientados para a ação (uso). A localização de um agente na rede é tomada como elemento chave para identificar seu Capital Social e poderia facilitar, mas não necessariamente determinar o acesso a melhores recursos da rede. Haveria de se imaginar uma relação não determinística entre: os fatores estruturais e a posição de cada agente na estrutura (e também de ativos coletivos como confiança, normas); o acesso e o uso do Capital Social; e os retornos do Capital Social, incluindo riqueza, poder e reputação, mas também saúde física e mental e satisfação pessoal (Lin, 1999).

É notável o encadeamento e a complementaridade das proposições de Burt (1980), de Granovetter (1985) e de Giddens (1989), aproveitadas em uma extensão considerável por Lin (1999) que, assim, poderia ser tomado como esforço integrativo daqueles que o precederam.

No entanto, Lin (1999) não trabalha com uma questão fundamental: pessoas em posições equivalentes em uma mesma rede, portanto, com um mesmo Capital Social potencial, têm a mesma estratégia de ação? Hipoteticamente, a resposta inicial é: DEPENDE. Depende, inicialmente, da percepção desses agentes em relação aos recursos disponíveis e, depois, de seu interesse em agir. 
Portanto, ao modelo de Lin caberia pelo menos a inclusão de mais um condicionante: a percepção que é o foco deste trabalho.

\section{O Papel das Instituições}

A teoria institucional também lida com questões referentes à estrutura e ao agente, procurando entender como uma instituição estrutura o comportamento humano, se ela é dependente da disposição dos agentes em comportar-se de tal forma. Para elucidar essa questão, os teóricos neoinstitucionalistas lançam mão de duas justificativas: a perspectiva calculadora e a perspectiva cultural.

Os adeptos da perspectiva calculadora postulam que os indivíduos buscam maximizar seu rendimento dentro de um conjunto de objetivos definidos por uma função preferência externa, adotando um comportamento estratégico: as pessoas examinariam todas as escolhas possíveis para selecionar aquelas que oferecem um benefício máximo. As instituições afetariam o comportamento, ao reduzir a incerteza dos atores quanto ao comportamento presente e futuro dos outros atores indicando os próprios mecanismos de aplicação dos acordos e as sanções correlatas. Já a perspectiva cultural parte do ponto de vista de que o comportamento não é inteiramente estratégico, mas limitado pela visão do mundo própria ao indivíduo - mesmo racional e orientado para fins - que recorre a protocolos estabelecidos ou a modelos de comportamento já conhecidos para atingir seus objetivos. A escolha de uma linha de ação dependeria da interpretação de uma situação mais do que de um cálculo puramente utilitário. As instituições agiriam como fonte de modelos morais e cognitivos que permitem a interpretação e a ação (Hall \& Taylor, 1996).

Dentro de cada uma das variantes do neoinstitucionalismo, que se diferenciam no grau de utilização das perspectivas calculadora e cultural, existe um grupo de proposições pertinentes à pesquisa, explicitadas a seguir.

As instituições tomam forma de procedimentos, protocolos, normas e convenções oficiais e oficiosas inerentes à estrutura organizacional da comunidade política ou da economia política (March \& Olsen, 1989). Podem assumir também a forma de sistemas de símbolos, esquemas cognitivos e os modelos morais que fornecem padrões de significação que guiam a ação humana. Atuam simultaneamente como limitadoras do comportamento e como estrutura de oportunidades que facilita a ação social (Nee, 1998).

As instituições afetam os custos de transações e, em consequência, afetam a forma de governança das organizações (North, 1994; Williamson, 1981).

Alguns procedimentos institucionais deveriam ser considerados como práticas culturais, comparáveis aos mitos e às cerimônias. As organizações adotariam formas e práticas institucionais particulares, porque elas têm valor largamente reconhecido em ambiente cultural mais amplo, o que lhes confere legitimidade social (Hall \& Taylor, 1996).

- As instituições atuam em diferentes dimensões: (a) regulativa, por meio de mecanismos coercitivos como regras, leis e sanções; (b) normativa, por meio da certificação e aceitação; (c) mimética, pelo predomínio e isomorfismo; e (d) cognitiva. Na dimensão regulativa, há que se considerar os custos do controle social, em suas parcelas informais, monitoramento e enforcement. Na dimensão normativa, as instituições socializam os indivíduos, levando-os a desempenharem papéis específicos, internalizando as normas associadas a esses papéis. Na dimensão mimética, as organizações se imitam e se modelam umas às outras, reduzindo as incertezas e alcançando uma legitimidade pela aceitação mútua (DiMaggio, 1995; DiMaggio \& Powell, 2004). Por meio da dimensão cognitiva, as instituições influenciam o comportamento, ao fornecer esquemas e modelos cognitivos que são indispensáveis à ação, mesmo porque, sem eles, seria impossível interpretar o mundo e o comportamento dos outros atores. As instituições influenciariam não apenas os cálculos 
estratégicos dos indivíduos, mas também suas preferências mais fundamentais (DiMaggio, 1995), o que é relevante para este trabalho.

\section{Método}

\section{Objeto de estudo}

O foco do estudo está nas ligações que os pesquisadores estabelecem entre si, que se manifesta na forma de uma rede atuante sobre a égide do CBP\&D/Café. O Consórcio, de acordo com Rufino (2006), mesmo dispensando a sua configuração em pessoa jurídica, foi criado em 1997 e é constituído por um conjunto de universidades e institutos de pesquisa que se encarrega de executar o Programa Nacional de Pesquisa e Desenvolvimento do Café (PNP\&D/Café), sob a coordenação da Empresa Brasileira de Pesquisa Agropecuária (Embrapa). Tal Consórcio procura atender à demanda de diversos clientes: produtores de café, consumidores; certificadoras; beneficiadoras; empresas produtoras de insumos; associações, confederações e conselhos e cooperativas - mediados pelo Conselho Deliberativo da Política do Café (CDPC), órgão do Ministério da Agricultura, Pecuária e Abastecimento, mediante a aplicação de recursos oriundos das próprias executantes e de um fundo federal (Funcafé). Entre a sua criação em 1997 e 2006, o CBP\&D/Café executou 889 subprojetos, implementados por 50 entidades, despendendo 87 milhões de reais em recursos do Funcafé (não se computando o volume das contrapartes alocado pelos consorciados).

O Consórcio é apoiado por dois elementos que atuam conjuminados: (a) a rede burocrática coordenada pela Embrapa e (b) a rede social entre os pesquisadores e entre as suas entidades que se articulam entre si para propor projetos em resposta às chamadas dos editais publicados pela rede burocrática e/ou para a elaboração e a publicação de artigos relacionados à pesquisa do café. As duas redes atuam simultaneamente e apoiam o Consórcio, submetidas ao imperativo do financiamento de pesquisa.

A rede de pesquisadores foi revelada pela análise sociométrica de (a) coautorias em artigos científicos publicados em anais de Simpósios e Congressos; (b) participação dos pesquisadores em projetos no Consórcio; (c) indicações de pesquisadores parceiros preferenciais (obtido do questionário, como descrito na próxima seção).

\section{Coleta e tratamento dos dados}

Procurou-se preservar a validade e a confiabilidade da pesquisa, buscando-se a triangulação dos métodos de pesquisa (qualitativos e quantitativos) empregados. A abordagem qualitativa se fez presente na análise de conteúdo da documentação e da transcrição das gravações das entrevistas e das reuniões. A fase quantitativa consistiu na análise sociométrica de publicações, de propostas de pesquisa e das escolhas preferenciais, além do emprego de técnicas estatísticas descritivas e multivariadas, incluindo as técnicas de correlação, análise discriminante e análise de cluster.

Antes das entrevistas semiestruturadas de pessoas relevantes na rede de pesquisadores e no Consórcio, foi feita a análise documental, com os objetivos de familiarizar o responsável pela pesquisa com o Consórcio e seus integrantes e de personalizar as questões a serem utilizadas nas fases subsequentes. Em paralelo, empregou-se uma análise de coautoria, utilizando o software PAJEK, com o objetivo de revelar objetivamente os laços entre pesquisadores e entre as suas entidades. A análise de conteúdo das entrevistas com elementos centrais das entidades centrais, além de constituir uma das evidências da pesquisa, prestou-se ao segundo refino das questões a serem empregadas na survey. Do universo de responsáveis pelos projetos e subprojetos (397 pesquisadores) do Consórcio, todos convidados, obtiveram-se 236 respostas. O principal instrumento de coleta da survey foi um aplicativo comercial que convertia as respostas em tabelas. Daí os dados foram transferidos para o software 
Statistical Package for the Social Sciences (SPSS), o que facilitou os meios para os estudos de correlação, análise de conglomerados e análise discriminante.

As entrevistas e a sua análise de conteúdo constituíram o cerne da investigação. Mesmo quando não se pretendeu investir na epistemometodologia do construcionismo, as falas dos pesquisadores de café foram tidas como significativas e alusivas aos processos de construção de significados sobre o Consórcio e sobre a rede justaposta a ele, pelo menos para esses agentes. Isso porque se admitiu que os objetos são apreendidos, compreendidos, passam a ter sentido e, mais ainda, daí são instituídos, a partir de categorias, convenções, práticas e linguagem (Spink \& Frezza, 2004). Em decorrência e de forma mais direta, a rede seria o que se diz, e o que não se diz dela: a prática discursiva seria central no processo de tornar real a rede, ainda mais sendo ela um ente incorpóreo e, como tal, desprovido de fronteiras.

Os entrevistados foram selecionados entre aqueles que responderam por maior volume das verbas de pesquisa repassadas pelo Consórcio, naquelas entidades mais centrais da rede. Foram 39 entrevistas, ao longo dos meses de setembro a dezembro de 2007, junto aos pesquisadores das seguintes instituições: Empresa Brasileira de Pesquisa Agropecuária (Embrapa), Universidade Federal de Viçosa (UFV), Universidade Federal de Lavras (UFLA), Instituto Agronômico (IAC), Instituto Agronômico do Paraná (IAPAR), Instituto Capixaba de Pesquisa, Assistência Técnica e Extensão Rural (INCAPER) e Empresa de Pesquisa Agropecuária de Minas Gerais (EPAMIG). No total, foram gravados 3.232 minutos, com média, por entrevista, de 83 minutos, sendo a mais curta de 34 minutos, a mais longa, de 172 minutos. No final, admite-se que o contingente submetido à entrevista não se aproxima, nem era essa a pretensão, de uma amostra representativa do corpo de pesquisadores do café no Brasil. Eles foram escolhidos a propósito entre os elementos mais centrais, dentro das organizações mais centrais participantes do Consórcio. O painel foi constituído de uma elite: apenas três participantes com titulação inferior a doutor e, entre os doutores, onze com bolsa de produtividade do CNPq. Movimentaram uma fração desproporcional de valores do Consórcio: 39 indivíduos entre 397, portanto $10 \%$ daqueles responsáveis por subprojetos, com presença tal que responderam por 28,5 milhões de reais, ou seja, um terço do total de recursos disponibilizados pelo Consórcio, entre 1997 e 2006.

O questionário, totalmente estruturado e apenas com opções fechadas, foi composto de 12 conjuntos de questões. As primeiras questões tiveram objetivos demográficos, como identificar a dedicação ao café, o núcleo de referência, a titulação e a situação em face do CNPq. Na questão 5 pediu-se ao respondente que encaixasse a sua visão sobre o Consórcio em 12 pares de categorias, à semelhança da Escala de Diferenciação Semântica de Osgood. Já na questão 6, pedia-se a indicação de dois pesquisadores que o respondente mais provavelmente teria preferência para uma parceria dento de um projeto a ser submetido à apreciação do Consórcio. O objetivo foi montar um sociograma que indicasse o capital de prestígio dos agentes, testar valores como a transdisciplinaridade e a multiinstitucionalidade e confirmar a centralidade da rede de coautorias. Na questão 9, era solicitado aos pesquisadores que indicassem o seu grau de concordância, de baixa a alta concordância, em face de 26 afirmações em uma escala tipo Likert de sete pontos. As afirmações diziam respeito à percepção do respondente quanto aos procedimentos adotados pelo Consórcio ou pela Embrapa na cooptação, julgamento, financiamento e acompanhamento de propostas de pesquisa. Para a elaboração da questão 9, foi admitido como hipótese que pessoas com visões diferentes do Consórcio poderiam reagir de forma diferente às afirmações.

A população de pesquisa para a aplicação do questionário foi definida como composta pelos pesquisadores responsáveis por subprojetos contratados entre 1997 e 2006. Dessa forma, a população somou 397 pesquisadores.

A aplicação do questionário se deu no período compreendido entre 20 de fevereiro e 10 de abril de 2008. A amostra obtida foi qualificada como não estatística. Da população de 397 responsáveis por subprojetos, 236 responderam ao questionário. Esse número é superior ao mínimo objetivado (200) e corresponde a 59\% da população, mas que administrou $70 \%$ das verbas destinadas à $\mathrm{P} \& \mathrm{D}$ em projetos contratados junto ao Consórcio entre 1997 e 2006. Os pesquisadores restantes foram enquadrados em 
Inacessíveis (31 pesquisadores, 8\% da população); Recusantes (29 pesquisadores, 7\% da população) e Omissos (105 pesquisadores, 26\% da população).

\section{Resultados e Discussão}

Ao mesmo ponto em que os resultados sinalizam a consolidação de uma estrutura constituída pela rede de cientistas (que destaca e ao fazê-lo recompensa pesquisadores que ocupam posições centrais) e por um conjunto de regularidades e lógicas, que poderiam ser tomadas como instituições dentro do arranjo, foram também encontradas indicações da atuação de mecanismos que são da ordem do sujeito e da sua agência, em ação dual com a estrutura, tal como previsível a partir de Burt (1980), Giddens (1989), Granovetter (1985) e Lin (1999). Tal é apresentado e discutido a seguir.

\section{Visão dos pesquisadores sobre o consórcio}

Tanto as entrevistas quanto os dados obtidos do questionário apontam uma mesma direção: existe um gradiente de visões dos pesquisadores sobre o Consórcio. Isso permitiu utilizar dois critérios para classificar os pesquisadores. O primeiro critério adveio dos pares dicotômicos da questão 5 do questionário, enquanto a reação às afirmativas da questão 9 do instrumento respondeu pelo segundo critério. O primeiro classificou os pesquisadores (através da técnica Two Step Cluster do SPSS) em pessoas com visão Confiante ou com visão Descrente; o segundo critério, da mesma forma, classificou as pessoas que se manifestaram de forma Favorável e Desfavorável. Os dois agrupamentos foram tidos como consistentes, com coeficiente de correlação de 0,450, significativo em nível de $1 \%$ (teste Kendall`s tau_b). Pesquisadores, que se tenham manifestados de forma favorável ao CBP\&D/Café, em face das afirmações da questão 9, foram encontrados mais frequentemente no grupo Confiante - e de forma oposta, pessoas com opiniões desfavoráveis se verão inscritos mais frequentemente no grupo Descrente. Pessoas com visão Descrente tendem a manifestar-se em oposição ao Consórcio, enquanto os pesquisadores com visão Confiante têm pequena tendência de manifestar-se de forma favorável ao CBP\&D/Café. É evidente que não se trata de padrão absoluto; mas, mesmo assim, reforça os argumentos favoráveis à consistência da participação dos respondentes.

Foram feitas diversas tabulações cruzadas entre os grupos e as visões que lhe deram origem, procurando caracterizá-los. Assim, o grupo Confiante é constituído predominantemente por pessoas que assim acham o Consórcio: democrático, transparente, voltado ao produtor, abrangente, mais favorecido que ameaçado pelo ambiente, com foco prático, alocador eficiente de recursos, definidor de rumos, meritocrático, dotado de impulso inovativo e em ascensão. Em oposição, encontra-se o grupo Descrente, composto predominantemente por pessoas que percebem o Consórcio como oligárquico, opaco, voltado ao pesquisador, dispersivo, mais ameaçado que favorecido pelo ambiente, alocador ineficiente de recursos, condicionado externamente, político, continuísta, e em declínio. Essa discriminação foi submetida ao teste de significância estatística com resultados satisfatórios: Phi e Cramer próximos de zero.

Um mesmo Consórcio é visto como político ou meritocrático. A depender dessa percepção, teorias de ação distintas podem ser vislumbradas. No questionário, 125 respondentes acham o Consórcio político em face de 71, que o consideram meritocrático. Para esses últimos, a teoria de ação mais natural seria manter o engajamento e empregar esforços para fazer o melhor (tecnicamente) projeto possível. Quanto ao primeiro grupo, as opções têm um leque maior. Alguns podem afastar-se do Consórcio. Outros, se periféricos, podem buscar alianças que elevem as suas chances e/ou investir para amealhar posições proveitosas. Aqueles centrais podem aceitar as regras do jogo e buscar usufruir as vantagens da posição, ou podem tentar mudar a situação (inclinar o Consórcio para a meritocracia), mesmo que isso eventualmente reduza as suas chances de se apropriar das oportunidades do arranjo.

Por outro lado, foram testados os agrupamentos com diversos indicadores sociométricos dos pesquisadores na rede, até mesmo o volume que cada um apropriou de verbas de pesquisa e o seu 
prestígio (advindo do indicador Authority Weight aplicado às indicações de parceiros preferenciais questão 6 do questionário, apurado pelo software PAJEK). Todas as correlações testadas falharam em explicar o gradiente de visão entre os pesquisadores - no que pode ser tido como um resultado inesperado: a visão do pesquisador sobre o Consórcio não pode ser dita condicionada pelo volume de verbas ou por seu prestígio, mesmo quando se comprova uma correlação estatisticamente significativa ( $r$ de 0,561, significativo em nível de 1\%) entre verba amealhada para pesquisa e o prestígio do pesquisador. Mesmo nas entrevistas, todas com pessoas centrais em entidades centrais, encontraram-se pesquisadores igualmente divididos, com visão oposta a cada ponto específico levantado, exceto quanto a ser o Consórcio uma boa ideia em sua concepção.

\section{Lógicas das parcerias no consórcio}

Enquanto os dados das entrevistas e do questionário se apoiam mutuamente na caracterização das disparidades das visões dos pesquisadores, eles divergem quanto à motivação e critérios para as parcerias.

Pelo questionário, a alternativa apontada como benefício importante para a maior fração dos respondentes foi o acesso a novos conhecimentos. Desenvolvimento da rede de parceria apareceu em segundo. Claro está que esse benefício é um benefício-meio: amplia-se a rede para aferir as demais vantagens. O que chama a atenção é a pequena frequência de respondentes que apontaram satisfação pessoal e reputação como benefícios importantes derivados da participação em projetos do Consórcio.

Para usufruir tais vantagens, os respondentes do questionário atestaram formar parcerias priorizando a complementaridade de conhecimentos para se obter mais conhecimento. Reputação, bem como amizade teriam papel secundário; tanto como critério de seleção quanto como benefício obtido, indicação em desacordo com a teoria de rede, movida a poder, dinheiro e reputação.

Contudo as entrevistas mostram um quadro que se afasta das respostas do questionário. À lógica da dependência de recursos (não apenas de conhecimento, mas também de recursos materiais) se juntam outras lógicas, como a afetiva e a da proximidade, na explicação das ações empreendidas pelos agentes da rede, como se exemplifica em alguns dos depoimentos, de diferentes entrevistados.

\section{· Lógica afetiva}

"Quando você se dá bem com um professor, você faz. Mas, num é institucional; assim, a instituição como instituição que obriga o cara a pesquisar, a trabalhar em conjunto com o pesquisador tal. Num vem de cima. Isso aí começa a construir em baixo... Eu procurei apoio de um professor da UFLA e ele, de boa vontade, que é meu amigo, e tal e tal, aceitou fazer o trabalho. Aí, nós fazemos o trabalho junto".

“Na verdade, essas parcerias não são entre instituições, são entre pesquisadores... porque a parceria é sempre entre os pesquisadores... Vai ser sempre por afinidade”.

\section{Lógica da proximidade física}

"Por que aqui a UFV tem com a EPAMIG? Porque tem vários pesquisadores da EPAMIG aqui dentro da UFV, fisicamente aqui dentro, tá? Mesma coisa a EPAMIG com a UFLA. Agora, não existe ninguém da UFLA aqui dentro da UFV e nem ninguém da UFV dentro da UFLA".

\section{- Lógica histórica}

"Por exemplo, se você encontra, deve tá no negócio, uma ligação muito forte entre UFV e UNIUBE. Quer dizer, ela é fortuita. Por quê? Porque o cara da UNIUBE, ele tem irrigação. Ele deve ter uns sete, oito projetos, todo ano junta ali... É tudo irrigação. É por quê? O Mantovanni foi orientador do... do André, que é o cara que, hoje, é o chefe da irrigação da UNIUBE”.

“Naquele projeto nosso, é... num é por acaso, por causa das minhas relações com aqueles pesquisadores, das nossas relações, nós tivemos um projeto que tinha um cara de Campinas, um cara do Paraná, dois na verdade, e um cara de Lavras, trabalhando num projeto”. 


\section{· Lógica voltada ao sucesso}

"Pelo fato do Consórcio exigir da gente, a gente procura outras instituições. Isso aí a gente procura mesmo. Mas é muito fácil. Você arranjar duas instituições é a coisa mais fácil que tem. Então é..., mas a gente procura mais porque é mais fácil você, por exemplo, entrar num projeto de peso (...) Algumas pessoas que trabalham e são mais conceituadas nesta área estão aí... Tem a competência. Tem as razões de você fazer o projeto. Então... quem é que vai negar isto? A gente procurou estabelecer parcerias por estas razões também”.

Por fim, mais duas lógicas. (a) Lógica do imperativo dos editais: os pesquisadores aceitam os ditames dos editais e buscam parcerias, nem sempre aquelas necessárias mas a entendida como mais competitiva. "Hoje, a gente faz uma coisa fragmentada, junta por conveniência,..., Esse próprio edital da Embrapa, que estimula esse tipo de parceria... Mas eu acho que a gente, assim, dribla essa exigência". "Fica a cargo da gente mesmo formar essas parcerias que, na verdade, funcionam num projeto que a gente estabelece, mas, na prática, não”; e (b) Lógica ótima: dado o problema a ser resolvido, há um esforço em construir parcerias que melhor possam tratar da questão, considerando todos os recursos e capacidades requeridas, visando construir um "projeto articulado e integrado, harmônico e dotado de sinergia”.

\section{Padrões e regularidades no ambiente de pesquisa de café no Brasil}

As entrevistas revelaram o componente institucional, representado pelos padrões e regularidades, presentes no ambiente de pesquisa de café no Brasil. Tais regularidades, mesmo aquelas não absolutas, foram encontradas atuantes sobre uma parte preponderante dos pesquisadores de café. Os padrões são decorrentes tanto do ambiente maior - da pesquisa científica - quanto gerados dentro do próprio arranjo. Independentes de sua gênese, são importantes, na medida em que simplificam as transações, facilitam a comunicação, suprem parâmetros de pertencimento, atuam como convenções, favorecem ou inibem as ligações e assumem características ideológicas. As regularidades significativas encontradas foram:

1. Destacada das demais está a forma de fazer ciência. A maioria dos pesquisadores, circunscritos às ciências naturais, está condicionada pelos princípios e métodos caros ao funcionalismo: objetividade, experimentação e racionalidade.

2. Conhecimento como bem público. Não se disputa a questão do financiamento público das pesquisas e tampouco a livre circulação de seu produto. Arranjos com empresas: no caso, de herbicidas, de defensivos, de adubos e de máquinas e implementos agrícolas, são suspeitos de não cientificidade e rebaixados à categoria de experimentação. Valorização da difusão e transferência de tecnologia, levando o cientista a abarcar o papel dos extensionistas, escusando-se sob o mote de fazer prospecção da demanda.

3. Conhecimento como bem supremo. O cientista abnegado, capaz de devotar horas sem fim à produção do conhecimento - mesmo à custa da saúde física e do distanciamento de bens materiais - sobre a bancada de ensaios, nos meandros da burocracia, nas viagens desgastantes, no sem fim de relatórios e demandas várias.

4. Cientista como ser racional. Declaração reiterada de motivação puramente racional para escolhas e ações, desprovidas de caráter afetivo.

5. Cientista como arrecadador de recursos. As entidades de pesquisas, como universidades, institutos e mesmo a Embrapa, não asseguram os fundos para custeio das pesquisas, que devem ser buscados junto aos organismos de fomento. Como consequência, há valorização da habilidade de construir alianças e conceber projetos competitivos e alinhados com os editais e políticas das agências financiadoras.

6. Cientista como gestor de recursos. A continuidade das pesquisas exige ininterrupto suprimento de recursos, incompatível com o fluxo irregular das disponibilidades. Em função disso, decorre a 
valorização da flexibilidade para transferir recursos, à medida que se disponha de múltiplos projetos em andamento.

7. Cientista como unidade nas ligações. As entidades que congregam os cientistas, independentemente de ser universidade, instituto ou empresa, não exercem papel constitutivo nas ligações; as parcerias envolvem pesquisadores, são criadas e sustidas nessa esfera.

8. Apropriação discursiva de valores: democracia, meritocracia, transparência, produtividade e, em menor escala, transdisciplinaridade e multi-institucionalidade estão presentes nos discursos dos pesquisadores.

9. Demonização de comportamento identificado como político. A defesa de interesses de classe ou individual é tida como ruptura nefasta da ordem meritocrática, elemento intruso e extemporâneo.

10. Idealização do Consórcio. Ponto de partida discursivo, do tipo: “Consórcio foi uma boa idéia...”, confrontado com a realidade.

11. Intrusão da lógica do mercado. A equação básica é equilibrar a demanda privada de tecnologia com a oferta pública de conhecimento, mediante a livre concorrência em editais de demanda induzida. O objetivo seria atender ao cliente da pesquisa (os produtores e a indústria). O método é a resolução de problemas sob uma ótica produtivista: maior eficiência na utilização dos fatores de produção.

12. Reificação de entidades. O discurso dos pesquisadores é permeado de ocasiões em que eles concedem sentimentos, emoções e ações às entidades, da forma: "a UFV tem ciúmes da UFLA"; "a Embrapa exigiu...”; e "a UFLA e a EPAMIG se dão bem, porque uma tá dentro da outra”. Nesse efeito, as entidades se tornam independentes das pessoas que realmente sentiram e agiram. É um recurso economizador, mas que comunica uma imagem totalizante como se todos os pesquisadores da UFV tivessem ciúmes da UFLA; e se presta a aliviar a carga sobre os agentes reais a quem deveriam ser imputados os sentimentos e ações.

13. Eterna vigilância. Os pesquisadores se demonstraram competentes em discursar sobre a própria rede, sobre os recursos (financiamento, prestígio), sobre as posições e seus ocupantes e sobre o comportamento estratégico dos pares, dentro da rede. Tal grau de circulação de informação, mesmo facilitada pela coesão da rede, exige diligenciamento, não seria gratuito e é útil na seleção de parceiros e em outras ações concebidas com o propósito de defender ou expandir as chances de sucesso dos atos desses pesquisadores.

Os elementos dos grupos Confiante e Descrente demonstraram, nas entrevistas, graus indistintos de subserviência a esses treze basilares. Assim como também demonstraram níveis semelhantes de monitoração (a) das ações empreendidas pelos parceiros-competidores; (b) dos recursos circulantes e apropriados na rede; e (c) das interferências externas atuantes sobre o arranjo. A circulação de informação é facilitada pela extensão da rede. Em contrário, a apregoada extensão da rede defendida pelo grupo gestor, de 1.500 pesquisadores e 45 entidades participantes, tem um eixo central composto de oito entidades e poucas dezenas de pesquisadores (algo próximo a 80). Dentro desse eixo, as ações têm alta visibilidade. Tal eixo tem grau elevado de estabilidade, aferido pela correspondência entre os indicadores estruturais da rede de coautorias, nos últimos oito anos, o que favorece a reprodução de um conjunto de lógicas.

Cada parceria pode ser explicada combinando-se graus variáveis desse conjunto de lógicas. A lógica da homofilia (os pesquisadores centrais preferem pesquisadores também centrais); a lógica do mundo pequeno (os pesquisadores periféricos preferem os pesquisadores centrais); e a lógica do sucesso (parcerias são criadas na expectativa de que a reputação dos membros interfira positivamente no julgamento das propostas): são por definição, dependentes da posição dos agentes na rede. Se elas fossem preponderantes, haveria uma relação entre a estratégia das ligações e os indicadores estruturais do agente na rede. Para testar essa relação, seria preciso investigar as motivações das ligações em cada projeto submetido ao Consórcio e em cada relação de coautoria. Provavelmente, se inquiridos 
diretamente, os pesquisadores se subordinariam à lógica ótima: é aquela que melhor corresponde ao discurso estribado nos treze basilares. Isso é inferido pela reação dos pesquisadores às questões 7 e 12 do questionário, referentes à motivação para as ligações preferenciais e aos resultados obtidos pela ação no Consórcio. Nove em dez pesquisadores indicaram a complementaridade de competências como determinante importante da sua opção. Reputação, proximidade física, amizade e possibilidade de aprovação dos projetos (esse, um a cada dez pesquisadores) são reconhecidas como importantes por uma fração menor de respondentes. Esses mesmos pesquisadores valorizam o acesso a novos conhecimentos e o desenvolvimento da rede de parcerias como os resultados mais importantes advindos da participação no Consórcio. Aumento de reputação só é admitido como importante por um em cada cinco respondentes. No entanto, mesmo não admitindo como prática pessoal, os pesquisadores enxergam a incidência de outras lógicas no conjunto dos projetos.

\section{Considerações Finais}

Para além das indicações das parcerias entre os pesquisadores de café no Brasil, propõe-se que os dados empíricos encontrados e analisados corroboram, em uma extensão considerável, as bases teóricas apresentadas no começo do artigo. Não que fosse esse seu objetivo, circunscrito em expor a percepção dos pesquisadores de café sobre a sua rede e discutir a lógica de suas ligações. Mas seria razoável assinalar a presença de características estruturais (como as instituições, aqui, lógicas e regras incidentes e reproduzidas pelos pesquisadores nas suas atividades colaborativas, atuantes por meio de mecanismos coercitivos, normativos, mimétricos e cognitivos) e de características relacionais (a própria rede, com seu número de vértices e de ligações, configurando um espaço dotado de posições assimétricas de acesso aos recursos da rede). O composto instituições-rede seria a face objetivista do fenômeno, por sua vez sujeita ao imperativo da agência, ao poder dos pesquisadores em perceber a situação de forma desigual e de adotar um comportamento estratégico com algum grau de liberdade sobre a sua posição na rede, alavancado e ao mesmo tempo limitado, contudo não determinado pelas conjecturas estruturais, essas gozando de alguma estabilidade relativa (caso contrário, não se configurariam em um objeto útil e aceito, ou não seriam dependentes da sua reprodução, da ação dos agentes). Tal complexidade implica a sujeição à proposição dual de Giddens (1989) e/ou da postura estruturalista-construtivista de Bourdieu (1997), antecipadas por Berger e Luckmann (1966) e absorvidas em alguma medida por Burt (1980), Granovetter (1985) e Lin (1999).

Sinteticamente, deparou-se que a formação de redes requer dos agentes investimentos, em termos de tempo, atenção e, mesmo, financeiro, para criar e manter as ligações. Parte desse investimento se daria de forma consciente (estratégica); outra, por força do habitus e ainda outra, por mera imitação isomórfica (ainda que isso produza uma legitimação diante dos pares) ou por pressão das instituições presentes na rede. O investimento consciente somente seria realizado, porque os agentes imaginam que irão receber compensações superiores aos investimentos aportados. As compensações se dariam de diversas e entrelaçadas formas, em termos de informações valiosas, legitimação, bem-estar físico-emocional, status, prestígio, poder e mesmo compensações mais econômicas: como, por exemplo, financiamento de projetos. Essas compensações seriam obtidas pela mobilização estratégica dos recursos contidos na rede: acessibilidade a informações, a pessoas com poder e a pessoas com prestígio. A mobilização dependeria da percepção que os agentes têm de sua posição e localização na rede, dos recursos disponíveis na rede e da própria dinâmica da rede, mormente no que tange à apropriação de recursos. O reinvestimento dependeria da percepção que os agentes têm das compensações obtidas e a realizar; a percepção não se obrigaria a refletir as características estruturais dos agentes nem as compensações reais obtidas. Contudo haveria retroalimentação entre percepção e as características estruturais e as compensações obtidas. Por fim, a percepção seria só em parte condicionada pela rede; em outra, seria um atributo da pessoa e, portanto, deve ser tida como variável relevante.

Tais asseverações puderam, em alguma medida, ser corroboradas pela coerência entre as indicações da análise de conteúdo e as da análise multivariada. Isso aumenta a possibilidade da 
veracidade das seguintes indicações, derivadas das evidências já apresentadas, e que, em conjunto, apontam as sete explicitações que seguem.

1. Seria incorreto subordinar a percepção dos pesquisadores a condicionantes estruturais, pelo menos àqueles submetidos a exame. Pesquisadores centrais percebem de forma diferente fenômenos relevantes para a rede. $\mathrm{E}$ isso não é determinado por posições de rede ou por alguma assimetria de informação. A rede é coesa - a informação circula. Os pesquisadores se posicionam, confiantes ou descrentes do arranjo, favoráveis ou desfavoráveis às práticas e à gestão do Consórcio, independentemente de serem pesquisadores centrais ou periféricos.

2. Sendo incorreta no âmbito do Consórcio, a subordinação da percepção a condicionantes estruturais em outras redes também pode ser passível de questionamento.

3. As estratégias são servidas pela combinação de diversas lógicas: da homofilia, do mundo pequeno, da proximidade física, histórica, afetiva, da dependência de recursos - bem como segundo a lógica voltada ao sucesso, a lógica do imperativo dos editais e a lógica ótima. Algumas dessas lógicas são atinentes a elementos estruturais; outras, como a lógica afetiva, são de caráter subjetivo. A subjetividade intrínseca dos sentimentos é relevante para a compreensão das ligações e da ausência delas.

4. As instituições estão presentes na gênese e na reprodução dos diversos padrões e regularidades observadas na rede de pesquisadores do café: a forma de fazer ciência; a aceitação do conhecimento como bem público e como bem supremo; o cientista como ser racional, como arrecadador de recursos, como gestor de recursos e como unidade nas ligações; a apropriação discursiva de valores; a demonização de comportamento identificado como político em detrimento da meritocracia; a idealização do Consórcio; a intrusão da lógica do mercado; a reificação de entidades e a eterna vigilância.

5. Admite-se que esses padrões não são distintos daqueles passíveis de serem observados em redes colaborativas apoiadas pelo mesmo paradigma positivista de fazer ciência (ciência normal). Afinal, as mesmas instituições que configuram o macroambiente da ciência no Brasil respondem por parte (não quantificável, no estágio atual da pesquisa) dos padrões e regularidades reproduzidos pelos pesquisadores de café.

6. Foi observada a distribuição desigual de recursos e de resultados, prevista na literatura de rede colaborativa: poucos com muito, muitos com pouco. De significativo é a permanência, explicável pelo círculo virtuoso ligado aos cientistas estrelas (de maior prestígio): a distinção inicial atrai novas oportunidades de parcerias, aumenta a visibilidade, amplia as chances de assumir cargos em comissão, alarga o volume de verbas amealhadas, o que corresponde a mais projetos e mais resultados a relatar em artigos científicos e a mais prestígio, diferencial em nova volta do círculo.

7. As organizações têm papel acessório: os agentes principais são os cientistas. Em apenas um caso (distanciamento entre a UFLA e a UFV), as organizações foram destacadas como significativas, atuando como inibidoras da ação dos pesquisadores.

As instituições, os padrões e regularidades, a rede, as posições estruturais, a organização burocrática e as interferências externas configuram o campo onde competem e colaboram os pesquisadores. As razões para a cooperação são aquelas correntes na literatura de rede. De interessante, aponta-se a relutância do pesquisador em reconhecer o prestígio como elemento central de sua atuação.

É nesse campo que o pesquisador pratica a sua agência: monitora e percebe os recursos e as limitações, se insere e aos colegas em posições na rede, mobiliza parcerias enquanto congela outras, propõe projetos, participa de comissões, exerce pressão, amealha verbas, disputa as bolsas, implementa pesquisas, escreve e revisa relatórios, acompanha os pupilos, publica resultados, defende posições, monitora os concorrentes e colaboradores potenciais, investe seu tempo, desgasta-se física e emocionalmente, acredita, protege, descrê e protesta. Ao fazê-lo, aprende: sempre que se apresenta 
uma dissonância (que confronta o padrão tomado como certo), as pessoas têm a oportunidade de sentir e se ver envolvidas pela experiência concreta, absorvida por meio de mecanismos subjetivos, encarregados de valorá-la. Mesmo que essas oportunidades sejam esparsas, imersas que estão no emaranhado de modelos mentais, padrões e regularidades facilitadoras em sua previsibilidade e universalidade, sempre se pode fazer diferente.

\section{Artigo recebido em 28.09.2010. Aprovado em 31.03.2011.}

\section{Referências}

Agranoff, R., \& MacGuire, M. (2001). Big questions in public network management research. Journal of Public Administration Research and Theory, 11(3), 295-326.

Ahuja, G. (2000). Collaboration networks, structural holes and innovation: a longitudinal study. Administrative Science Quarterly, 45(3), 425-455.

Araújo, U. P., Antonialli, L. M., Brito, M. J., \& Guerrini, F. M. (2010). Capital social em um consórcio de pesquisa. Revista de Administração de Empresas, 50(4), 90-110. doi: 10.1590/S0034-75902010000400006

Bercovitz, J., \& Feldman, M. (2011). The mechanisms of collaboration in inventive teams: composition, social networks, and geography. Research Policy, 40(1), 81-93. doi: 10.1016/j.respol.2010.09.008

Berger, P. L., \& Luckmann, T. (1966). The social construction of reality: a treatise on the sociology of knowledge. London: Penguin University Books.

Bourdieu, P. (1997). The forms of capital. In A. H. Halsey, A. H. Lauder, P. Brown, \& A. Wells (Eds.), Education: culture, economy, and society (pp. 46-58). New York: Oxford University.

Bozeman, B., \& Corley, E. (2004). Scientists' collaboration strategies: implications for scientific and technical human capital. Research Policy, 33(4), 599-616. doi: 10.1016/j.respol.2004.01.008

Burt, R. (1980). Actor interests in a social topology: foundation for a structural theory of action. Sociological Inquiry, 50(2), 107-132. doi: 10.1111/j.1475-682X.1980.tb00380.x

Burt, R. (1982). Toward a structural theory of action: network models of social structure, perception and action. New York: Academic Press

Buskens, V., \& Yamaguchi, K. (1999). A new model for information diffusion in heterogeneous social networks. Sociological Methodology, 29(1), 281-325. doi: 10.1111/0081-1750.00067

Corley, E., Boardman, P. G., \& Bozeman, B. (2006). Design and the management of multiinstitutional research collaborations. Research Policy, 35(7), 975-993. doi: 10.1016/j.respol.2006.05.003

Cummings, J. N., \& Kiesler, S. (2007). Coordination cost and project outcomes in multiuniversity collaborations. Research Policy, 36(10), 1620-1634. doi: 10.1016/j.respol.2007.09.001

DiMaggio, P. J. (1995). Culture and economy. In N. Smelser \& R. Swedberg (Eds.), The handbook of economic sociology (pp. 27-57). New Jersey: Princeton University.

DiMaggio, P. J., \& Powell, W. W. (2004). The iron cage revisited: institutional isomorphism and collective rationality in organizational fields. In F. Dobbin (Ed.), The new economic sociology (pp. 111-134). Princeton: Princeton University. 
Freeman, L. C. (2004). The development of social network analysis: a study in the sociology of science. Vancouver: Empirical.

Giddens, A. (1989). A constituição da sociedade. São Paulo: M. Fontes.

Gilsing, V., Nooteboom, B., Vanhaverbeke, W., Duysters, G., \& Oord, A. van den (2009). Network embeddeness and the exploration of novel technologies: technological distance, betweenness centrality and density. Research Policy, 37(10), 1717-1731. doi: 10.1016/j.respol.2008.08.010

Granovetter, M. S. (1985). Economic action and social structure: the problem of embeddedness. American Journal of Sociology, 91(3), 481-510.

Granovetter, M. S. (1990). The myth of social network analysis as a special method in the social sciences. Connections, 13(1-2), 13-16.

Hall, P. A., \& Taylor, R. C. R. (1996). Political science and the three new institutionalisms. Political Studies, 44(5), 936-957. doi: 10.1111/j.1467-9248.1996.tb00343.x

Hansen, M. T. (1999). The search-transfer problem: the role of weak ties in sharing knowledge across organization subunits. Administrative Science Quarterly, 44(1), 82-111. doi: 10.2307/2667032

He, Z.-L., Geng, X.-S., \& Campbell-Hunt, C. (2009). Research collaboration and research output. Research Policy, 38(2), 306-317. doi: 10.1016/j.respol.2008.11.011

Katz, J. S., \& Martin, B. (1997). What is research collaboration? Research Policy, 26(1), 1-18. doi: 10.1016/S0048-7333(96)00917-1

Landry, R., \& Amara, N. (1998). The impact of transaction costs on the institutional structuration of collaborative academic research. Research Policy, 27(9), 901-913. doi: 10.1016/S00487333(98)00098-5

Landry, R., Amara, N., \& Lamari, M. (2001). Social capital, innovation and public policy. Isuma: Canadian Journal of Policy Research, 2(1), 63-71.

Lin, N. (1999). Building a network theory of social capital. Connections, 22(1), 28-51. doi: 10.1108/14691930410550381

March, J. G., \& Olsen, J. P. (1989). Rediscovering institutions: the organizational basis of politics. New York: The Free.

Merton, R. (1979). The sociology of science. Chicago: University of Chicago.

Moody, J. (2004). The structure of a social science collaboration network: disciplinary cohesion from 1963 to 1999. American Sociological Review, 69(2), 213-238. doi: $10.1177 / 000312240406900204$

Nee, V. (1998). Source of new institutionalism. In M. Briton \& V. Nee (Eds.), The new institutionalism in sociology (pp. 1-17). New York: Russell Sage Foundation.

Newman, M. E. J. (2004). Coauthorship networks and patterns of scientific collaboration. PNAS, 101(1), 5200-5205. doi: 10.1073/pnas.0307545100

North, D. C. (1994). Custo de transação, instituições de desempenho econômico. Rio de Janeiro: Instituto Liberal.

Porac, J. F., Wade, J. B., Fiscer, H. M., Brown, J., Kanfer, A., \& Bower, G. (2004). Human capital heterogeneity, collaborative relationships, and publication patterns in a multidisciplinary scientific alliance. Research Policy, 33(4), 661-678. doi: 10.1016/j.respol.2004.01.007 
Rigby, J., \& Edler, J. (2005). Peering inside research networks. Research Policy, 34(6), 784-794. doi: 10.1016/j.respol.2005.02.004

Rijnsoever, F. J. van, \& Hessels, L. K. (2011). Factors associated with disciplinary and interdisciplinary research collaboration. Research Policy, 40(3), 463-472. doi: 10.1016/j.respol.2010.11.001.

Rost, K. (2011). The strength of strong ties in the creation of innovation. Research Policy, 40(4), 588604. doi: 10.1016/j.respol.2010.12.001

Rufino, J. L. S. dos (2006). Programa nacional de pesquisa e desenvolvimento do café: antecedentes, criação e evolução. Brasília, DF: Embrapa Informação Tecnológica.

Schumpeter, J. A. (1961). Teoria do desenvolvimento econômico. Rio de Janeiro: Fundo de Cultura.

Spink, M. J. P., \& Frezza, R. M. (2004). Práticas discursivas e produção de sentido. In M. J. P. Spink (Org.), Práticas discursivas e produção de sentidos no cotidiano (3a ed., pp. 17-40) São Paulo: Cortez.

Williamson, O. E. (1981). The economics of organization: the transaction cost approach. American Journal of Sociology, 87(3), 548-577. doi: 10.1086/227496

Yli-Renko, H., Autio, E., \& Sapienza, H. J. (2001). Social capital, knowledge acquisition, and knowledge exploitation in young technology-based firms. Strategic Management Journal, 22(67), 587-613. doi: 10.1002/smj.183

Ynalvez, M. A., \& Shrum, W. M. (2011). Professional networks, scientific collaboration, and publication productivity in resource-constrained research institutions in a developing country. Research Policy, 40(2), 204-216. doi: 10.1016/j.respol.2010.10.004 